\title{
Development and Evaluation of Cholestyramine- Amoxicillin Trihydrate-Loaded Gastro-Retentive Microspheres for Attaining Extended Therapeutic Effect Against H. Pylori Infection
}

\author{
Debashish Nayak, Kuldeep Rajpoot and Sunil K Jain* \\ Institute of Pharmaceutical Sciences, Guru Ghasidas Vishwavidyalaya (A Central University), India \\ *Corresponding author: Sunil K Jain, Institute of Pharmaceutical Sciences, Guru Ghasidas Vishwavidyalaya (A Central \\ University), Bilaspur (C.G.) 495 009, India
}

\section{ARTICLE INFO}

Received: 慧 August 12, 2020

Published: 蔧 August 24, 2020

Citation: Debashish Nayak, Kuldeep Rajpoot, Sunil K Jain. Development and Evaluation of Cholestyramine-Amoxicillin Trihydrate-Loaded Gastro-Retentive Microspheres for Attaining Extended Therapeutic Effect Against H. Pylori Infection. Biomed J Sci \& Tech Res 29(4)-2020. BJSTR. MS.ID.004847.

Keywords: Microspheres; Cholestyramine; Amoxicillin Trihydrate; Gastro-retentive Delivery; H. pylori
ABSTRACT

Objectives: This work was aimed to develop and evaluate formulations containing amoxicillin trihydrate (AMT) to confirm their therapeutic potential against Helicobacter pylori infection.

Materials and Methods: A drug-resin complex (DRC) was synthesized using AMT and cholestyramine and optimized. Afterward, this optimized DRC was loaded in the chitosan microspheres (MS) possessing dual qualities (i.e., floating and mucoadhesive).

Results: Floating MS were investigated for various parameters for instances, $\%$ mucoadhesion, particle size, and morphology, \%drug-entrapment efficiency (\%DEE), floating ability (in vitro), and drug release (in vitro) profile. Findings from optimized formulations suggested good DEE $(79.65 \pm 2.13 \%)$ of drug and average particle size $(106.49 \pm 4.45 \mu \mathrm{m})$. In addition, MS revealed decent buoyancy $(78.60 \pm 3.3 \%)$ and mucoadhesion $(78.25 \pm 0.14 \%$ ) ability along with good floating lag-time ( $>20 \mathrm{~min}$ ). On the other hand, in vitro results advocated sustained release profile of AMT for up to 24 h. As hypothesized, fluorescence (in vivo) study confirmed prolonged retention of MS in the stomach.

Conclusion: MS with dual qualities can be used for attaining encouraging results (in vitro) in the treatment of infection caused by Helicobacter pylori.

Abbreviations: DRC: Drug-Resin Complex; MS: Microspheres; AMT: Amoxicillin Trihydrate; GI: Gastrointestinal; MEC: Minimum Effective Concentration; MSC: Maximum Safe Concentration; CR: Cholestyramin; CH: Chitosan; EC: Ethyl Cellulose; DCM: Dichloromethane; PVA: Polyvinyl Alcohol; SCM: Scanning Electron Microscopy; SGF: Simulated Gastric Fluid

\section{Introduction}

The Helicobacter pylori infection mostly affects peoples having age more than 60 years (occurrence rate $=60 \%$ ), on the other hand, the rate of occurrence in young populations is $10 \%$. However, in highdensity areas where population accommodates in poorly hygienic conditions as well as bad food habits increase chances of infection. Several times, this infection advanced mutely and contained merely in the gastric area devoid symptoms [1]. To combat this issue, it requires an effective approach by which retention of drug carrier system can be prolonged in the stomach to release drug in a sustained manner. Hence, eradication of Helicobacter pylori can be achieved by developing a floating carrier system containing that can deliver therapeutic agents for an extended time in the stomach area. In this context, gastro-retentive formulations proved to be a useful strategy for longer homing of therapeutic agents. Further, 
due to enhance of the homing period of formulation in the stomach, these systems result in augment of the bioavailability of the drug, maximum utilization of the drug, as well as sustained release effect of molecules at higher $\mathrm{pH}$.

Therefore, the application of these systems encourages the sitespecific delivery of therapeutic agents in the gastrointestinal (GI) domain. In our previous works, the gastro-retentive-based approach has shown promising results for effective delivery of many drugs, for instances, acetohydroxamic acid, clarithromycin, amoxicillin, and ciprofloxacin against H. pylori [2-6]. The gastro-retentivebased approach has depicted not only high retaining aptitude for drugs in the stomach but also showed a controlled release pattern of the drug through formulations via exploiting mucoadhesive affinity toward mucosal surface. Hence it produces an immense effect in treating stomach associated illnesses. In addition, this strategy has also been utilized to enhance bioavailability of drugs and attaining a steeper concentration gradient (by using relatively lesser drug), which usually improve performance of drug by maintaining its concentration in the given therapeutic window (i.e., minimum effective concentration (MEC) $\leq$ therapeutic window $\geq$ maximum safe concentration (MSC)). Furthermore, such kind of systems may decrease some undesirable toxic effects due to sitespecific (mucoadhesive property) delivery of drug, which restricts unnecessary distribution of drug to other tissues/organs $[7,8]$.

Scientists are paying more attention to synthesize drugresin complexes (DRC) as they show an appealing property of maintaining sustained and controlled release of drug. Further, coating of DRC with polymers may not only avoid incidence of dose dumping following delivery but also leaching of the drug during storage, which would also improve its stability. Moreover, several resins are employed in the formation of DRC for instance, resins of hydrophobic nature and cross-linked porous polymeric chains that comprised of exchangeable inorganic functional groups. However, these groups on resins can be easily replaced with the ions or active moieties possessing similar charge $[9,10]$. The exceptional properties of resins such as long polymeric chains, level of crosslinking, and availability of functional groups offer a more consistent drug release pattern over other polymer matrices systems [11]. Furthermore, these resins exhibit extra flexibility to formulate a wide range of systems for efficient delivery of drugs, for example, suspensions [12,13], beads [14], microparticles [15,16], tablets $[17,18]$, liposomes [19], and simple matrices [17]. Cholestyramine (CR) is an anion-exchange resin, which exhibits bio/mucoadhesive properties [20] via exploiting electrostatic interaction amid mucin and epithelial cell surface.

For instance, CR in DRC may encourage its adhesion with gastric mucosa, which results in elevated gastric retention of DRC $[21,22]$. Some DRCs are being developed by employing ion exchange resins and antibiotics such as amoxicillin [23], cimetidine [24], tetracycline [25], etc. These DRCs have demonstrated their worth as a better approach for efficient targeting and treatment of $H$. pylori infections (fundus) in the stomach. Nevertheless, it has been observed challenging with conventional dosage forms. Amoxicillin trihydrate (AMT) is an antibiotic, which exhibits broad-spectrum activity and is widely utilized for the therapy of Helicobacter pylori infection. AMT shows some prominent characteristics such as fast absorption following oral administration, good biological activity ( $\mathrm{t} 0.5=0.7$ to $1.4 \mathrm{~h}$ ), and decent stability in an acidic environment [26].

The main goal of this study was to fabricate gastro-retentive microspheres (MS) of AMT for efficient therapy of Helicobacter pylori infection. To fulfill this objective, CR was selected as an ion exchange resin, while AMT was taken as an antibiotic drug. Briefly, the DRC was prepared using CR and AMT, then it was encapsulated in the MS synthesized by polymers namely chitosan $(\mathrm{CH})$ and ethyl cellulose (EC). Afterward, MS was characterized for various parameters (e.g., drug-entrapment efficiency, DEE) and evaluated in vitro for drug release as well as in vivo GI transit time.

\section{Materials and Methods}

\section{Materials}

AMT was received through M/s Aurobindo Pharma Limited (Ahmedabad, India) as a kind gift. CR-resin (also called Tulsion 412) was procured from Thermax Limited (Pune, India). CH (85\% deacetylated and $\mathrm{MW}=65 \mathrm{kDa}$ ) was procured as a gift sample through Central Institute of Fisheries Technology (Cochin, India). EC was bought from HiMedia (Mumbai, India). Animal studies were conducted as per IAEC guidelines and approved (Reference No.: IAEC/Pharmacy/2012/19) by the IAEC of Guru Ghasidas Central University, Bilaspur, Chhattisgarh, India (CPCSEA Regd. No: 994/a/ G0/06/CPCSEA).

\section{Purification and Activation of CR-Resins}

CR (10 g) was cleaned by successive use of deionized water (DW, $5 \mathrm{ml}$ ) (thrice), ethanol of two different concentrations (95.0\%, $150 \mathrm{ml}$, and 50.0\%, $50 \mathrm{ml}$, respectively), and DW (50 ml) [27]. The washing was performed under continuous agitation on a magnetic stirrer for $60 \mathrm{~min}$. Afterward, it was treated with $2.0 \mathrm{M}$ of $60 \mathrm{ml}$ of $\mathrm{NaOH}$ and $\mathrm{HCl}$ abide by washing with DW (twice). Eventually, CR was obtained via filtration process by subjecting vacuum as well as it was thoroughly cleaned with DW. Finally, it was dried at $40{ }^{\circ} \mathrm{C}$ for $12 \mathrm{~h}$ under the hot-air oven.

\section{Synthesis of DRC}

DRC was synthesized via employing a previously reported batch process $[27,28]$. In this regard, different ratios of AMT and CR-resin were mixed as described in (Table 1). Moreover, cleaned CR-resin was mixed in the $25 \mathrm{ml}$ methanolic AMT solution and then agitated for $4 \mathrm{~h}$ on the stirrer (MacroScientific Works, India). Afterward, different prepared batches were passed amidst Whatman ${ }^{\circledR}$ 
cellulose filters (\#41). Thus, obtained AMT-encapsulated resin was freed from free AMT after washing with purified water. In the next step, filtrate comprising free AMT was analyzed at $272 \mathrm{~nm}$ under UV-1800 Spectrophotometer (Shimadzu, Japan). The quantity of AMT bound with CR-resin was calculated by subtracting unbound (free) AMT from the initial total AMT added. This filtered AMTencapsulated mass was dried at temperature of $40{ }^{\circ} \mathrm{C}$ for $12 \mathrm{~h}$ in the oven. DRC having best AMT-binding efficiency and relatively a lesser amount of utilized resin was selected as an optimum DRC for further synthesis of MS. All investigations were made in triplicate.

Table 1: Coding of AMT-resin complex and drug-loading efficiency.

\begin{tabular}{|c|c|c|}
\hline $\begin{array}{c}\text { Assigned } \\
\text { code }\end{array}$ & $\begin{array}{c}\text { Ratio of AMT: resin } \\
\mathbf{( w / w )}\end{array}$ & $\begin{array}{c}\text { Drug-loading efficiency (\%) } \\
\text { after } \mathbf{4 h}\end{array}$ \\
\hline DRC1 & $1: 1$ & $50.56 \pm 0.24 \%$ \\
\hline DRC2 & $1: 2$ & $65.17 \pm 0.31 \%$ \\
\hline DRC3 & $1: 3$ & $66.83 \pm 0.12 \%$ \\
\hline DRC4 & $1: 4$ & $68.15 \pm 0.42 \%$ \\
\hline
\end{tabular}

Note: DRC, Drug-resin complex; and Data are the average of values, mean \pm S.D. $(n=3)$.

\section{Formulation of MS}

Solvent evaporation technique was employed for the synthesis of DRC-loaded MS [3]. Further, $5 \mathrm{ml}$ of solution of each EC and $\mathrm{CH}$ were prepared using dichloromethane (DCM) and acetic acid $(2.0 \%$ $\mathrm{v} / \mathrm{v}$ ), respectively. Afterward, both solutions were mixed homogeneously under constant stirring (10 $\mathrm{min}$ at $1000 \mathrm{rpm}$ ) on stirrer abide via ultrasonication (Frontline, India) for $5 \mathrm{~min}$. Afterward, the optimized DRC was added to the resultant solution of polymer EC and $\mathrm{CH}$ with continuous stirring to get a uniform mixture. This dispersion was then mixed in the $300 \mathrm{ml}$ of aqueous polyvinyl alcohol (PVA) solution $(0.45 \% \mathrm{w} / \mathrm{v})$ at $35{ }^{\circ} \mathrm{C}$ through a needle (\# 24) with constant stirring. The dispersed droplets were allowed to evaporate DCM for 45 min to form spherical MS. Afterward, MS were separated by decantation process subsequent to several cleaning with DW. Collected MS were dried at $40{ }^{\circ} \mathrm{C}$ for two-days in the oven and then it was kept in the desiccator for further evaluation. To compare the effectiveness of DRC over the polymeric system, a batch of drug-incorporated non-resinate MS (NRMS) was also synthesized via employing a similar method and adding an equal proportion of EC, $\mathrm{CH}$, and AMT-polymer (1:1) ratio (Table 2).

Table 2: Batch specifications and micromeritic studies of the prepared formulations.

\begin{tabular}{|c|c|c|c|c|c|c|c|c|c|}
\hline $\begin{array}{l}\text { Formulation } \\
\text { code }\end{array}$ & $\begin{array}{c}\text { DRC: polymer } \\
\text { ratio }(w / w)\end{array}$ & $\begin{array}{l}\text { Polymer ratio } \\
(w / w)(E C: C H)\end{array}$ & $\begin{array}{l}\text { Particle } \\
\text { size }(\mu \mathrm{m})\end{array}$ & $\begin{array}{c}\text { Tapped } \\
\text { density }(\mathrm{g} / \\
\left.\mathrm{cm}^{3}\right)\end{array}$ & $\begin{array}{c}\text { True } \\
\text { density }(\mathrm{g} / \\
\left.\mathrm{cm}^{3}\right)\end{array}$ & $\begin{array}{c}\text { Compressibility } \\
\text { index }(\%)\end{array}$ & Porosity (\%) & Yield(\%) & $\begin{array}{c}\text { Drug } \\
\text { entrapment } \\
(\%)\end{array}$ \\
\hline MS-1 & $1: 1$ & $5: 5$ & $60.25 \pm 2.56$ & $0.78 \pm 0.01$ & $0.86 \pm 0.04$ & $25.45 \pm 0.66$ & $56.34 \pm 0.69$ & $65.42 \pm 0.98$ & $62.48 \pm 0.56$ \\
\hline MS-2 & $1: 1$ & $6: 4$ & $73.11 \pm 2.37$ & $0.74 \pm 0.02$ & $0.79 \pm 0.34$ & $28.15 \pm 0.65$ & $62.45 \pm 1.98$ & $70.73 \pm 1.49$ & $69.03 \pm 0.34$ \\
\hline MS-3 & $1: 1$ & $7: 3$ & $86.35 \pm 4.70$ & $0.68 \pm 0.02$ & $0.45 \pm 0.03$ & $31.41 \pm 0.34$ & $69.78 \pm 1.22$ & $75.89 \pm 0.76$ & $75.40 \pm 1.39$ \\
\hline MS-4 & $1: 1$ & $8: 2$ & $96.67 \pm 5.69$ & $0.61 \pm 0.01$ & $0.84 \pm 0.01$ & $37.40 \pm 0.34$ & $70.90 \pm 3.71$ & $76.44 \pm 3.59$ & $77.46 \pm 2.02$ \\
\hline MS-5 & $1: 1$ & $9: 1$ & $\begin{array}{c}106.49 \pm \\
4.45\end{array}$ & $0.59 \pm 0.06$ & $0.73 \pm 0.07$ & $32.16 \pm 0.37$ & $75 . .40 \pm 1.45$ & $80.15 \pm 2.45$ & $79.65 \pm 2.13$ \\
\hline NRMS & - & $1: 1$ & $55.47 \pm 0.39$ & $0.48 \pm 0.03$ & $0.89 \pm 0.05$ & $34.25 \pm 0.49$ & $47.34 \pm 0.34$ & $86.34 \pm 0.42$ & $84.32 \pm 0.65$ \\
\hline
\end{tabular}

Note: EC, Ethyl cellulose; CH, Chitosan; MS, Microsphere formulation; NRMS, non-resinatemicrospheres; and Values are mean \pm S.D. $(n=3)$.

\section{Morphology and Micromeritic Studies}

The morphology of the developed DRC as well as optimized preparation was determined under scanning electron microscopy (SEM) (JSM 5600 JEOL, Japan). Briefly, the samples were mounted on a stub covered with clean glass. Later on, samples were gold coated and investigated under SEM. However, particle size of AMT, CR-resin, DRC, as well as formulations was monitored via employing optical microscopy. In addition, MS were also evaluated for compressibility index, tapped- as well as true-density. All investigations were conducted three-times.

\section{Fourier Transformed-Infrared (FTIR)}

FTIR investigations were conducted for different samples of drug (AMT), CR-resin, EC, CH, DRC, and formulations under FTIR8400S spectrophotometer (Shimadzu, Japan). Briefly, powder sample and potassium bromide (KBr) were uniformly mixed (95:5), and then it was kept inside the sample holder for investigation. The spectrum of sample was recorded in a range from 4000 to $400 \mathrm{~cm}^{-1}$.

\section{\%Yield and \%DEE}

After synthesis, the filtered MS were dried under the desiccator. After drying, MS was weighed accurately in triplicate to get statistically justified results [27]. The below-described formula was employed to determine \%yield:

$$
\text { Yield }(\%)=\frac{\text { Total weight of microspheres }}{\text { Total weight of DRC and polymers }} X 100
$$

The MS (200 mg) was transferred to a closed vessel to dissolve them in the DCM (10 ml). Further, it was agitated using the magnetic stirrer for $2 \mathrm{~h}[2,29]$. Afterward, the drug was eluted by using $0.4 \mathrm{M}$ $\mathrm{HCl}(50 \mathrm{ml})$. In the next step, eluent was decanted and replenished 
with a similar volume of the fresh eluent. The decanted elute was assayed at $272 \mathrm{~nm}$ for AMT concentration spectrophotometrically. The sum of AMT amount in all portions of elute was considered as the total amount of AMT. The below-mentioned equation was employed to calculate \%DEE:

$$
D E E(\%)=\frac{\text { Calculated drug content }}{\text { Theoretical drug content }} \times 100
$$

\section{Percent Mucoadhesion}

Mucoadhesive effect of formulations was examined using albino rats (150-200 g). For the same, two animals (male) were kept per cage under ambient conditions $\left(20-25^{\circ} \mathrm{C}\right)$ with a constant supply of meal and water. For investigations, animals were humanely sacrificed by cervical dislocation.[2] In the next step, stomach was removed and divided into sections $(2.0 \mathrm{~cm}$ long and $1.0 \mathrm{~cm}$ wide), which were then washed using the physiological saline (pH 1.2) solution. Approximately 100 mg (Wo) of MS was sprinkled superficially on the mucosa of the stomach. Afterward, it was monitored after placing it in the examining chamber. During the study, conditions were upheld at $93 \%$ relative humidity with ambient temperature. However, after 20 minutes, the tissue was removed, and then it was kept at $45^{\circ}$ using polyethylene support. The stomach mucosa was bathed using the saline solution of $\mathrm{pH}$ 1.2. Further, the flow rate of saline was maintained at $20 \mathrm{ml} / \mathrm{min}$ for $5 \mathrm{~min}$. After washing, MS were collected, dried, and weighed (Wun). Finally, \%binding efficiency of MS was calculated using the below formula:

$$
\operatorname{Binding}(\%)=\frac{W_{o-} W_{u n}}{W_{o}} \times 100
$$

\section{Buoyancy Investigations (in vitro)}

Floating ability of MS (in vitro) was determined by using USP dissolution test apparatus (type-II). Approximately $50 \mathrm{mg}$ of MS formulation was sprinkled in the $900 \mathrm{ml}$ of simulated gastric fluid (SGF, pH 1.2), which is also containing $1.0 \% \mathrm{w} / \mathrm{v}$ Tween ${ }^{\circledR} 80$. Further, the study was performed at constant [30]. The medium was constantly stirred by the use of paddle (at $50 \mathrm{rpm}$ ) for $12 \mathrm{~h}$ and its temperature was maintained at $37 \pm 0.5^{\circ} \mathrm{C}$. After study, both floating as well as settled portions containing MS were collected, dried, and weighed separately. Eventually, buoyancy of MS was determined as per below formula [31].

$$
\text { Buoyancy }(\%)=\frac{W_{f}}{W_{f}+W_{s}} \times 100
$$

Where Wf represents weights of the floating MS and Ws indicate a settled amount of MS.

\section{Drug Release Investigations (in vitro)}

The drug (AMT) release pattern from MS was examined by employing a dissolution apparatus (i.e., USP basket) [32]. Approximately $50 \mathrm{mg}$ of MS was packed into a capsule of size \#5 and then it was kept into the basket containing $900 \mathrm{ml}$ of dissolution medium (SGF, pH 1.2). During the study, the temperature of the system was constantly kept at $37 \pm 0.5^{\circ} \mathrm{C}$. Further, fluid medium was rotated at the speed of $100 \mathrm{rpm}$. Nearly $5 \mathrm{ml}$ of fluid containing dissolved drug was taken out at specified time periods i.e., $0.5 \mathrm{~h}$ and then it was filtered using Whatman filter paper (\#41). Finally, samples were analyzed to determine drug content at $272 \mathrm{~nm}$ spectrophotometrically. Throughout the experiment, the amount of fluid was maintained constant by mixing prewarmed fluid ( $5 \mathrm{ml}$ ) medium at specified intervals. Similar procedure was also followed for the dissolution study of NRMS and marketed tablet of AMT (E-Mox, 200 mg, Marline Bio care, UK). The release pattern of AMT through CR-resin-based MS formulations, NRMS formulation, DRC, as well as marketed preparation of AMT (E-MOX) was examined statistically by applying ANOVA subsequent to Dunnett's multiple comparison post-test $(\mathrm{p}<0.05)$.

The release pattern of drug through CR-resin complex can be explained via the two mechanisms. In first mechanism, the free drug is diffused through resin matrix [28]. On the other hand, in second mechanism the drug is usually diffused out from thin polymeric film of the resin particle. However, the release pattern of the drug could be controlled via the splitting rate of ionic bonds amid drug and resin. Further, it also depends on the rate of diffusion of drug across the polymeric network. If it is supposed that all DRC NPs show spherical shape (with radius $=r$ ) and followed a diffusion (rate-limiting step) based drug release mechanism through matrix. The below-described equation can be used to calculate fraction (F) of drug released:

$$
F=\frac{Q_{t}}{Q_{\infty}}
$$

For $\mathrm{F}>0.85$

$$
\begin{gathered}
F=1-\frac{6}{\pi^{2}} e^{-B t} \\
B t=-\log _{e} \frac{\pi^{2}}{6}(1-F)=-\ln (1-F)-0.04977 \\
B t=-2.303 \log _{10}(1-F)=-0.04977
\end{gathered}
$$

For $\mathrm{F}<0.85$

$$
B t=2 \pi-\frac{\pi^{2} F}{3}-2 \pi\left(1-\frac{\pi F}{3}\right)^{1 / 2}
$$

$$
B t=6.283-3.290 F-6.283(1-1.047 F)^{1 / 2}
$$

Where Qt represent quantity of drug after time t, Q $\infty$ denotes total quantity of drug in resin, and constant, B is the exchange rate (per minute).

Further, the value of Bt can be plotted against the experimental value of $t$. However, Bt was determined through Eqs. (2) and (3) by 
placing value of $\mathrm{F}=0.85$, which suggested its value within 0.005 in response to $\mathrm{F}<0.001$ [33]. If the plot graph for $\mathrm{Bt}$ against values of $\mathrm{F}$ vs time generates a straight line, then it can be presumed that the diffusion-based released of drug is the rate-limiting step for the resin matrix [17]. On the other hand, Bhaskar expression [34] is also utilized to determine diffusion-based controlled release of drug through resin particles (Eq. 8):

$$
\ln (1-F)=\ln \frac{Q_{0}}{Q_{t}}=1.59\left(\frac{6}{d p}\right)^{1.3} D^{0.65} t^{0.65}
$$

Where $\mathrm{F}$ represents a fraction value of drug dissolved, $\mathrm{dp}$ designate average diameter $(\mathrm{mm})$ of the resin particles, D denote diffusion coefficient $\left(\mathrm{mm}^{2} / \mathrm{min}\right)$, and t represents time.

Further, this is again extrapolated using a linear relationship amid $-\ln (1-F)$ and t0.65 [12]. The release of drug through the swellable matrix of particles can be explained by employing formula given by Ritger and Peppas (Eq. 9 and 10) [35].

$$
\begin{gathered}
\frac{M_{t}}{M_{\infty}}=K \times t^{n} \\
\log \left(\frac{M_{t}}{M_{\infty}}\right)=\log k+n \log t
\end{gathered}
$$

Where $\mathrm{Mt}$ and $\mathrm{M}_{\infty}$ denote amount of drug dissolved in solution after time $t$, and the complete amount of drug-encapsulated, $n$ represents type of mechanism followed by the release. If the values of $\mathrm{n}$ exist in range from 0.45 to 0.85 , then it suggests diffusions as well as swelling controlled release mechanism, however, if they obtained values are more than 0.85 , then it advocates case II type of transport mechanism [27].

\section{GI Transit Studies}

The GI transit of sodium fluorescein loaded (AMT-free) MS was determined on Sprague-Dawley male rats (200-300 g) [36]. In this context, fluorescein-resin complex (FRC) was synthesized via adding purified CR-resins in the sodium fluorescein solution (including 25\% additional marker pertaining to the ion-exchange ability of the resin) followed by uninterrupted stirring for $24 \mathrm{~h}$ at ambient temperature. Further, synthesized complex was collected via vacuum filtration. However, unreacted fluorescein was obtained following washing the complex with DW and then they were dried. Finally, fluorescein content was determined by analyzing it by spectrofluorometric method. Briefly, fluorescein content recorded from solution was subtracted from initial fluorescein content. FRC- based MS was synthesized according to the method stated for the AMT-resin complex. Before treatment, rats were allowed for fasting (excluding water) for $24 \mathrm{~h}$. The DRC (15 mg) as well as MS (45 $\mathrm{mg}$ ) were administered orally with the help of glass syringe fitted to a cannula using $2 \mathrm{ml}$ of water so that it can reach right into the stomach.

Afterward, three rats were killed at different intervals (i.e., 1, 3, and $5 \mathrm{~h}$ ). In addition, distribution study was conducted to examine the effect of various formulations in distinct domains of the GI tract at predefined time intervals. Eventually, various parts of GI tract were dissected and cut to open lengthwise, for instance, stomach, duodenum $(3 \mathrm{~cm})$, jejunum $(35 \mathrm{~cm})$, and ileum, and then they were examined under a fluorescence microscope.

\section{Results and Discussion}

\section{Purification of CR-Resin and its Activation}

The purification of the CR-resin was performed via cleaning with DW and ethanol of two concentrations (i.e., 95\% and 50\%) [4]. By using these solvents, distinct impurities from CR-resin were removed via the filtration method. However, this method activates the CR-resin and then they are used for synthesis of complex amid AMT and bicarbonate ion. However, the extent of bicarbonate produced by CR-resin in the filtrate was determined via the titrimetric Sodium bicarbonate analysis. Further, titration study confirmed that free bicarbonate utilized nearly $6.43 \mathrm{ml}$ of 0.1 $\mathrm{M}$ of hydrochloric acid to neutralize it, which was found equivalent to $0.54 \mathrm{~g}$ of Sodium bicarbonate. Moreover, total quantity of bicarbonate, which was used by $10 \mathrm{~g}$ of CR-resin was approximately 2.606 g (i.e., $0.260 /$ g of CR-resin).

\section{Synthesis of DRC and AMT-Loading}

$\mathrm{CR}$ is a potent anionic-exchange resin that holds property to replace its anion group (chloride) with anionic drug and thus it develops a CR-drug complex along with hydrochloric acid. Hence, synthesis of DRC exploits the complexation of AMT by replacing COO- of AMT with Cl- of CR resin [35] (Figure 1). The \% loading of AMT in CR-resin was reported to be higher with three proportions (i.e., 1:2, 1:3, and 1:4) as compared to proportion, 1:1 of DRC (Table 1). However, findings suggested an insignificant difference ( $p>0.05$ ) in loading of AMT against proportions 1:2, 1:3, and 1:4. Moreover, DRC with proportion 1:2 (DRC2) was selected for further study owing to its high drug loading efficiency as compared to two other ratios i.e., $1: 1,1: 3$, and 1:4. 


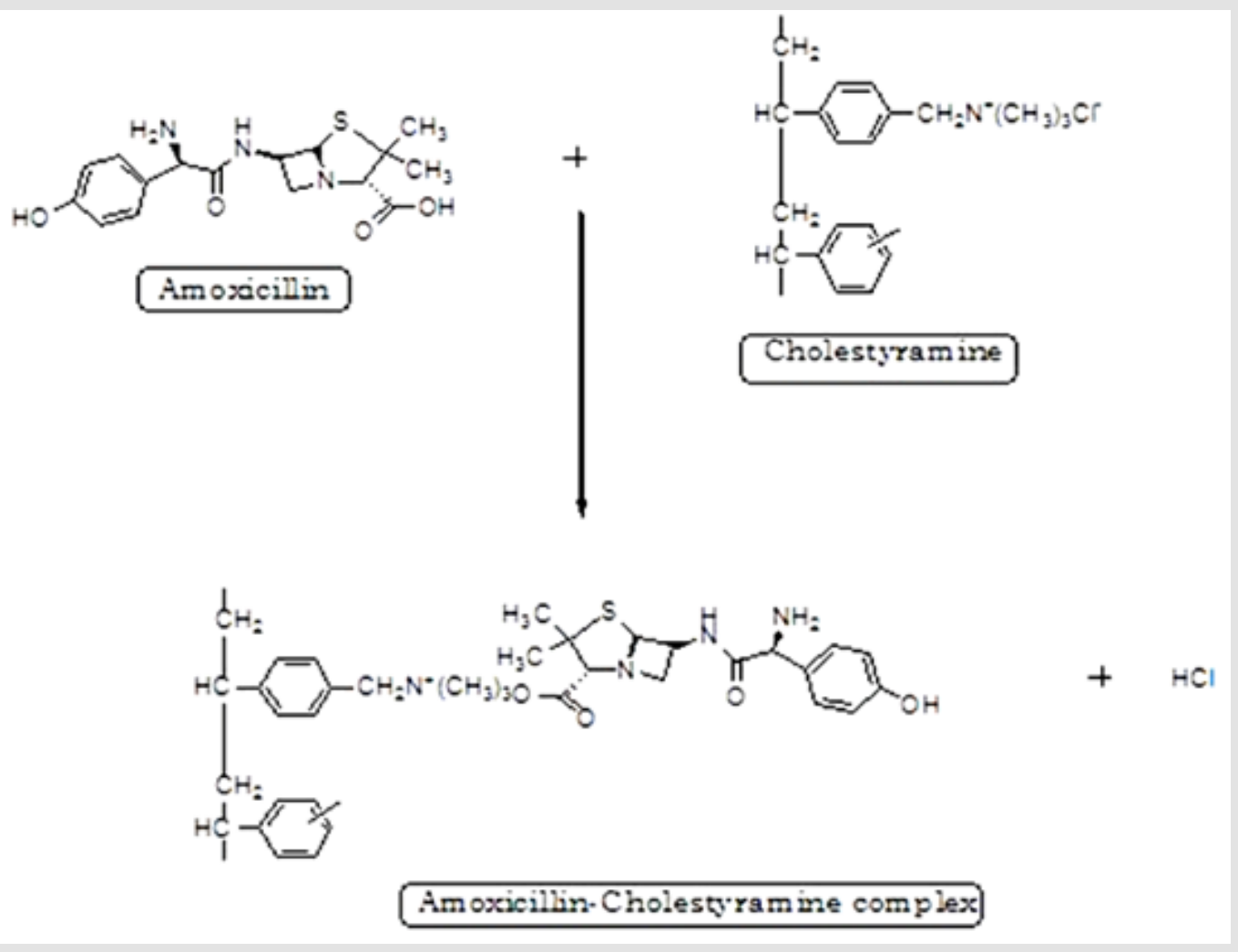

Figure 1: Schematic showing formation of AMT-resin complex.

\section{Preparation of MS}

The synthesis of MS was achieved by dispersing DCM solution already containing EC, $\mathrm{CH}$, and DRC2 into the aqueous solution containing PVA at $35{ }^{\circ} \mathrm{C}$ under constant agitation. Further, gradual evaporation of the DCM encouraged the formation of MS. Findings suggested that polymers-saturated solutions developed smooth surface as well as obtained a great percentage of MS [37]. On the other hand, unsaturated-polymers yields rod-structured particles having an uneven surface. However, rotation speed also played an important role to control both \%yield as well as particle size of the MS. It was observed that the enhance in the speed of the propeller from 300 to $700 \mathrm{rpm}$ also reduced mean particle size of MS without affecting their morphology (data not shown). Study also confirmed aggregation and separation of polymer above optimum speed (i.e., at more than $1000 \mathrm{rpm}$ ) [9].

\section{Shape and Surface Morphology}

The DRC2 showed a rough exterior appearance, which could be possibly due to the adsorption of little amount of AMT at the surface of resin (Figure 2A). MS images confirmed several pores at the surface, which suggested that drug could diffuse freely from the complex (Figures 2B \& 2C). However, these pores might be formed owing to the successive removal of the encapsulated DCM from the surface of particles at the time of the synthesis of MS [32].

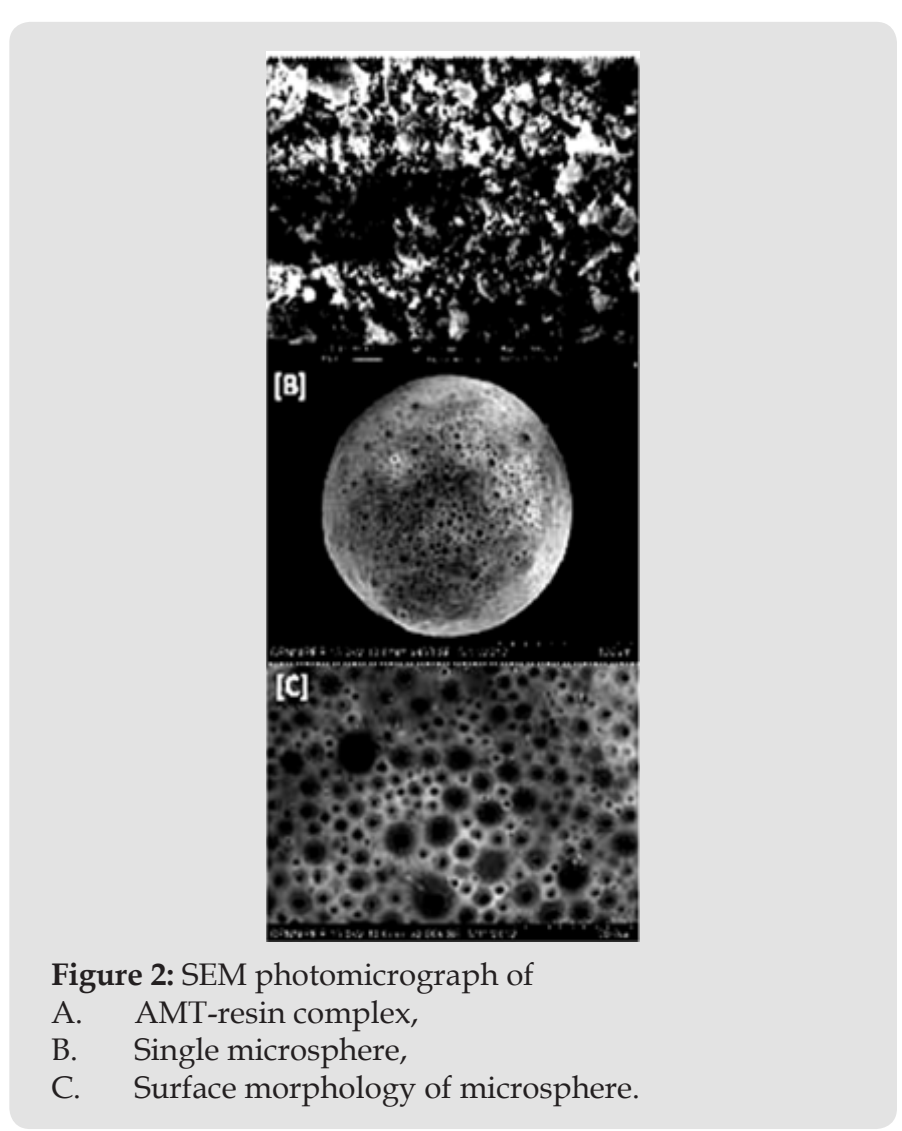




\section{Micromeritic Studies}

The mean size of DRC2 was observed to be $22.43 \pm 2.45 \mu \mathrm{m}$, which was seen marginally high to that of normal particles obtained from pure CR-resin (i.e. $12.77 \pm 1.9 \mu \mathrm{m}$ ) suggesting the existence of AMT in it. However, size of the synthesized MS was observed from $60.25 \pm 2.56 \mu \mathrm{m}$ to $106.49 \pm 4.45 \mu \mathrm{m}$ (Table 2). Moreover, size of MS was enhanced with the augment in the proportion of polymer. In addition, as the quantity of resinate was enhanced, the size of MS was also escalated, this could be owing to the resinate that could have filled the interstitial spaces amid polymer subdivisions [16]. The tapped density was found from $0.48 \pm 0.029 \mathrm{~g} / \mathrm{cm}^{3}$ to $0.78 \pm 0$. $011 \mathrm{~g} / \mathrm{cm}^{3}$, on the other hand, the true density was observed amid $0.45 \pm 0.034 \mathrm{~g} / \mathrm{cm}^{3}$ and $0.89 \pm 0.053 \mathrm{~g} / \mathrm{cm}^{3}$. However, both density values were observed less than 1 , which indicated that the MS was freely floating in the gastric content. The \%compressibility index values of the MS were found between $25.45 \pm 0.66$ and $37.40 \pm 0.34$, which suggested good flow characteristics of the MS.

\section{FTIR Study}

The recorded FTIR spectrum of AMT exhibited a prominent peak at $1315 \mathrm{~cm}^{-1}$ owing to the attached thiazolidine $\beta$ lactam skeletal. It produced peaks at $1686 \mathrm{~cm}^{-1}$ owing to presence of an amide group and at $1782 \mathrm{~cm}^{-1}$ due to $\beta$ lactam ring. Further, it depicted peak at $1519 \mathrm{~cm}-1$ and $2970 \mathrm{~cm}^{-1}$ due to benzene ring and methyl stretching, respectively, and at $3463 \mathrm{~cm}^{-1}$ due to amide $\mathrm{NH}$ and $3175 \mathrm{~cm}^{-1}$ owing to phenol stretching (Figure 3A). However, resin was confirmed by identifying peak at $1030 \mathrm{~cm}^{-1}$ owing to the quaternary ammonium group (Figure 3B). Moreover, IR spectrum of DRC2 showed different characteristic peaks of AMT at 1780 $\mathrm{cm}^{-1}$ due to $\beta$ lactam ring, at $1683 \mathrm{~cm}^{-1}$ due to amide stretching of the drug in the resinate. Characteristic peaks of CR-resin in DRC2 was confirmed at $1030 \mathrm{~cm}^{-1}$ due to $\mathrm{C}-\mathrm{N}$ stretching of quaternary amine, which confirmed the development of complex amid AMT and CR-resin (Figure 3C). The IR spectrum of EC showed prominent peaks at $3625 \mathrm{~cm}^{-1}$ due to free $\mathrm{OH}$ group and $3100 \mathrm{~cm}^{-1}$ due to $\mathrm{C}$-H stretching (Figure 3D). The IR spectrum of $\mathrm{CH}$ showed strong peaks at $1359.47 \mathrm{~cm}^{-1}$ owing to $\mathrm{C}-\mathrm{N}$ stretching and $3095.24 \mathrm{~cm}^{-1}$ due to $\mathrm{C}-\mathrm{H}$ stretching (Figure 3E). Further, characteristic peak of DRC2 was recorded at $1349 \mathrm{~cm}^{-1}$ owing to $\mathrm{C}-\mathrm{N}$ stretching of the quaternary amine, which advocated the entrapment of DRC in the formulation. However, characteristic peak of EC was obtained at $3120 \mathrm{~cm}^{-1}$ owing to $\mathrm{C}-\mathrm{H}$ stretching as well as peak at 1359.47 $\mathrm{cm}^{-1}$ due to $\mathrm{C}-\mathrm{N}$ stretching suggesting the presence of $\mathrm{CH}$ in the preparation (Figure 3F).

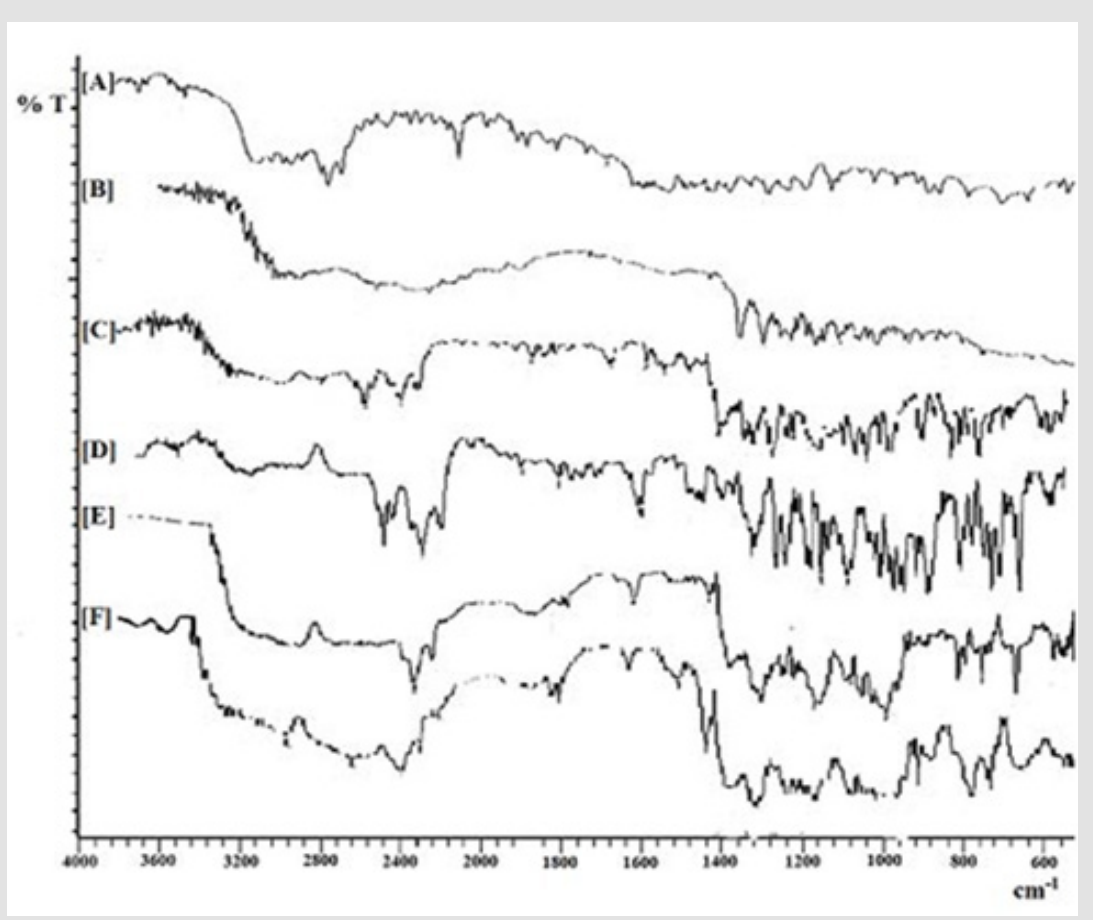

Figure 3: IR spectra of

(A) AMT,

(B) $\mathrm{CR}$,

(C) AMT-resin complex,

(D) $\mathrm{EC}$,

(E) $\mathrm{CH}$, and

(F) Microsphere formulation. 


\section{\%Yield and DEE}

\%Yield of the synthesized preparations was determined from $65.42 \pm 0.98 \%$ to $80.15 \pm 2.45 \%$. In contrast, DEE was observed in the range from $62.48 \pm 0.56 \%$ to $79.65 \pm 2.13 \%$ (Table 2). However, DEE was enhanced with the augment of concentration of the polymer, however, this could be owing to the extremely dense shape matrix system of cellulose as well as efficient loading of DRC particles [27].

\section{In vitro Buoyancy Behavior and Percent Mucoadhesion}

MS-3, MS-4, and MS-5 exhibited prolonged floating lag-time ( $>20 \mathrm{~min}$ ) than MS-1 and MS-2 (more than $10 \mathrm{~min}$ ). Moreover, this could be owing to the greater polymer proportion that also augmented path length for diffusion of MS via augmenting thickness of the polymer coat. Further, it exhibited decrease in the rate of the diffusion of hydrochloric acid into the DRC core, which also enhanced floating lag-time [38]. Mucoadhesive investigations were conducted to confirm the adhesion of the preparation to the mucosa for an extended-time. Mucoadhesiveness of the preparations was seen in the range from $60.34 \pm 0.94 \%$ to $78.25 \pm 0.14 \%$ (Table 3 ). Maximum mucoadhesion was determined for MS-1 as compared to other formulations, which could be owing to the high ratio of $\mathrm{CH}$ in the formulation. However, all the preparations revealed good mucoadhesive properties for the localization of the system for sufficient time.

Table 3: Mucoadhesion (\%) and in vitro floating behavior of the prepared formulations.

\begin{tabular}{|c|c|c|}
\hline Formulation code & Mucoadhesion (\%) & Buoyancy(\%) \\
\hline MS-1 & $78.25 \pm 0.14 \%$ & $58.39 \pm 1.9$ \\
\hline MS-2 & $77.62 \pm 0.38 \%$ & $65.98 \pm 4.5$ \\
\hline MS-3 & $71.43 \pm 0.12 \%$ & $72.77 \pm 3.9$ \\
\hline MS-4 & $66.50 \pm 0.45 \%$ & $75.89 \pm 2.5$ \\
\hline MS-5 & $60.34 \pm 0.94 \%$ & $78.60 \pm 3.3$ \\
\hline
\end{tabular}

Note: $\mathrm{MS}_{1-5}$, Microsphere formulations; and Values are mean \pm S.D. $(n=3)$.

\section{Drug Release Investigations (in vitro)}

Drug release investigation suggested that the release of AMT from NRMS was quicker than formulation containing DRC. Further, DRC formulation released AMT in a more controlled way owing to the formation of the complex of AMT with CR-resin. Furthermore, DRC2 released drug more rapidly (within $3 \mathrm{~h}$ ) as compared to its MS formulation. Findings suggested that drug-resin complex containing MS showed more sustainable release pattern than DRC and NRMS. The release of AMT from different formulations was observed in following order: DRC2 > NRMS > MS-1 > MS-2 > MS-3 $>$ MS-4 > MS-5. The results also advocated substantial influence of the polymer amount on the release of AMT pattern, i.e., greater the density of polymer lesser will be the diffusion of the drug from polymer [4]. Further, uncoated DRC2 showed a burst release (99.45 $\pm 0.3 \%$ within $3 \mathrm{~h})$, whereas NRMS $(80.15 \pm 0.45 \%$ within $8 \mathrm{~h}$ ) and MS-5 (54.65 $\pm 0.95 \%$ within $8 \mathrm{~h}$ ) showed much slower release rate than DRC2. So, effective encapsulation of DRC within the polymeric system is necessary for attaining sustained drug release effect. When cumulative release from the marketed formulation of AMT (E-MOX) is compared with MS-5, E-MOX, it showed a burst release of drug $(98.63 \pm 0.95 \%$ within $2.5 \mathrm{~h})$, on the other hand, MS-5 showed much slower release.

With these results, one can use this approach to encapsulate the DRC in polymeric systems to achieve a more sustained release of the incorporated drug (Figure 4). Drug release results of a marketed formulation of AMT (E-MOX) was compared with different formulations viz., DRC2, NRMS, and DRC2 containing formulations. The in vitro release study in the SGF ( $\mathrm{pH} 1.2$ ) of formulations suggested significant $(\mathrm{P}<0.01)$ effect except for DRC2 $(\mathrm{P}>0.05)$ (Table 4). In contrast, when data of NRMS was related with DRC2, E-MOX, as well as DRC2 comprising formulations in similar conditions, it was found less significant $(\mathrm{P}<0.05)$ in the preparations MS-5 and MS-4. Further, for DRC2 it was very significant $(\mathrm{P}<0.01)$ (Table 5). The results from Table 6 clearly indicated that the release kinetics of AMT through the MS preparations and followed diffusion-based controlled release of AMT. Further, release of drug was also observed through the pores present on the drugion exchange resin systems [39]. The release profile for AMT also fitted in Ritger-Peppas kinetics as confirmed via the correlation coefficient (greater than 0.95 ).

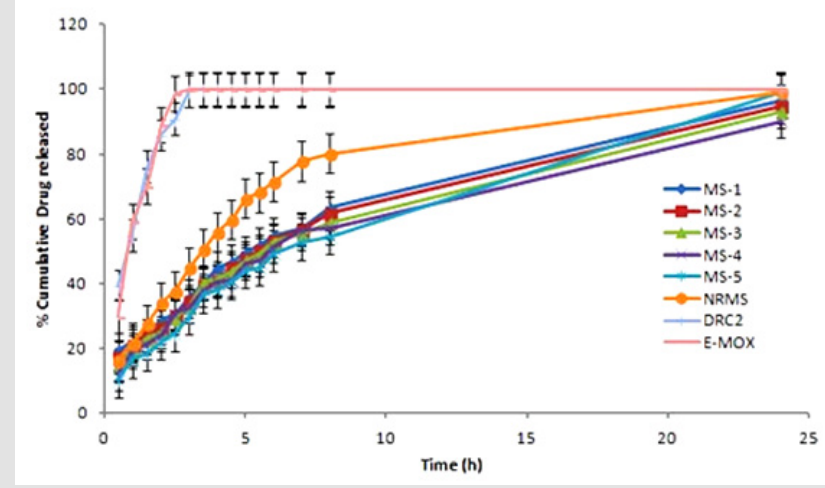

Figure 4: Comparison of in vitro drug release profile of prepared formulations and marketed product. NRMS, non-resinate microspheres; E-MOX, Marketed formulation of Amoxicillin trihydrate; DRC2, Drug resin complex; MS, Microsphere formulations; Values are mean \pm S.D. $(n=3)$.

Table 4: One-way ANOVA (Dunnett's multiple comparison) test for in vitro drug release of AMT in SGF ( $\mathrm{pH}$ 1.2).

\begin{tabular}{|c|c|c|c|}
\hline Comparison & Mean difference & $\mathbf{Q}$ & p-value \\
\hline E-MOX Vs DRC2 & -0.006000 & $0.0008027 \mathrm{~ns}$ & $\mathrm{P}>0.05$ \\
\hline E-MOX Vs MS-1 & 45.346 & $6.067^{* *}$ & $\mathrm{P}<0.01$ \\
\hline
\end{tabular}




\begin{tabular}{|l|l|l|l|}
\hline E-MOX Vs MS-2 & 46.886 & $6.273^{* *}$ & $\mathrm{P}<0.01$ \\
\hline E-MOX Vs MS-3 & 47.916 & $6.410^{* *}$ & $\mathrm{P}<0.01$ \\
\hline E-MOX Vs MS-4 & 49.187 & $6.580^{* *}$ & $\mathrm{P}<0.01$ \\
\hline E-MOX Vs MS-5 & 50.901 & $6.810^{* *}$ & $\mathrm{P}<0.01$ \\
\hline
\end{tabular}

Note: E-MOX, Marketed formulation of Amoxicillin trihydrate; $\mathrm{MS}_{1}$. ${ }_{5}$, Microsphere formulations; DRC2, Optimized drug-resin complex; ANOVA indicates analysis of variance; q, parameter obtained with p when performing ANOVA; **Very Significant; ns, Non-significant.

Table 5: One-way ANOVA (Dunnett's multiple comparison) test for in vitro drug release of AMT in SGF ( $\mathrm{pH}$ 1.2).

\begin{tabular}{|c|c|c|c|}
\hline Comparison & Mean difference & $\mathbf{Q}$ & $\mathbf{p}$-Value \\
\hline NRMS vs DRC2 & -35.667 & $4.782^{* *}$ & $\mathrm{P}<0.01$ \\
\hline NRMS vs MS-1 & 11.225 & $1.298 \mathrm{~ns}$ & $\mathrm{P}>0.05$ \\
\hline NRMS vs MS-2 & 12.656 & $1.505 \mathrm{~ns}$ & $\mathrm{P}>0.05$ \\
\hline NRMS vs MS-3 & 9.685 & $1.643 \mathrm{~ns}$ & $\mathrm{P}>0.05$ \\
\hline NRMS vs MS-4 & 25.342 & $2.985^{*}$ & $\mathrm{P}<0.05$ \\
\hline NRMS vs MS-5 & 23.569 & $2.778^{*}$ & $\mathrm{P}<0.05$ \\
\hline
\end{tabular}

Note: MS $_{1-5}$, Microsphere formulations; NRMS, non-resinate microspheres; DRC2, Optimized drug-resin complex; ANOVA indicates analysis of variance; $q$, parameter obtained with $p$ when performing ANOVA; **Very Significant; *Less significant; ns, Nonsignificant

Table 6: Release kinetics of microsphere formulations.

\begin{tabular}{|c|c|c|c|}
\hline \multirow{2}{*}{ Formulation code } & Reichenberg & Bhaskar & Ritger -Peppas \\
\cline { 2 - 4 } & $\mathbf{r}^{\mathbf{2}}$ & $\mathbf{r}^{\mathbf{2}}$ & $\mathbf{r}^{\mathbf{2}}$ \\
\hline MS-1 & 0.968 & 0.953 & 0.967 \\
\hline MS-2 & 0.956 & 0.959 & 0.960 \\
\hline MS-3 & 0.990 & 0.961 & 0.984 \\
\hline MS-4 & 0.957 & 0.985 & 0.991 \\
\hline MS-5 & 0.954 & 0.984 & 0.987 \\
\hline NRMS & 0.906 & 0.971 & 0.990 \\
\hline DRC2 & 0.646 & 0.652 & 0.984 \\
\hline E-MOX & 0.763 & 0.826 & 0.978 \\
\hline
\end{tabular}

Note: E-MOX, Marketed formulation of Amoxicillin trihydrate; $\mathrm{MS}_{1}$. 5, Microsphere formulation; NRMS, non-resinate microspheres; DRC2, Optimized Drug resin complex; and $\mathrm{r}^{2}$, Correlation coefficient.

The values of $\mathrm{n}$ (Ritger-Peppas) for MS preparations as well as DRC2 were seen amid 0.45 and 0.85 , however, it shows a clear sign of both diffusion and swelling controlled transportation mechanism (i.e., non-Fickian transport) of the AMT from MS. Drug release according to Ritger-Peppas model for DRC2 is in agreement with the results of Junyaprasert and Manwiwattanakul [12], Halder and Sa [16], and Jeong and Park [28]. During the drug kinetics study, it was found that NRMS has maximum $r^{2}$ value (0.984) for RitgerPeppas plot and very less value for Reichenberg's (0.646) and
Bhaskar's plot (0.652). Thus, the release of drug from NRMS is due to the diffusion of the AMT from the thin liquid film surrounding the particles.

\section{GI Transit of the Formulations}

Gastric residence of FRC and FRC loaded MS (fluorescein content $\approx 32.2 \pm 1.4 \% \mathrm{w} / \mathrm{w}$ ) was assessed via fluorescence microscopy of FRC loaded MS formulations (Figure 5). The micrographs showed different parts of the glandular segment of the stomach. Since glandular section in rodent is generally found smaller as compared to non-glandular segment, hence this region accumulated maximum particles. DRC-loaded MS were distributed in all over the gastric surface as swollen masses rather than discrete particles after $1 \mathrm{~h}$. However, very less had escaped further down the GI tract. After $3 \mathrm{~h}$, most of them still observed in the stomach and few more were found in duodenum and jejunum mucosa. After $5 \mathrm{~h}$ study, maximum particles were still seen in the stomach confirming prolonged retention of MS, though comparatively more particles observed in the ileum. Eventually, MS containing ion-exchange resin particles showed better retentive behavior in the stomach after 5 h study.

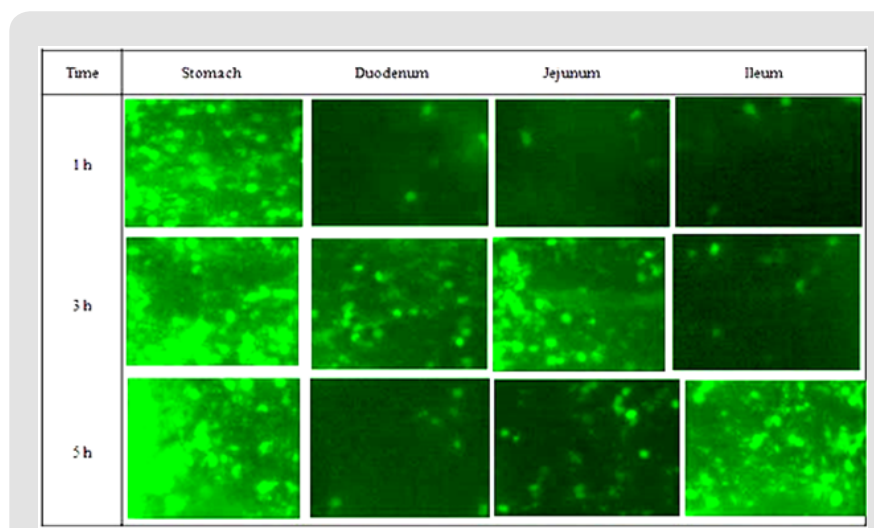

Figure 5: Fluorescence micrographs of GI segments at different time intervals after oral administration of FRCloaded MS.

\section{Conclusions}

The comparative results of different evaluation parameters reveal that CR-resin plays an effective role in controlling the release of AMT. Findings from optimized formulations suggested small particle size $(106.49 \pm 4.45 \mu \mathrm{m})$ with good entrapment efficiency $(79.65 \pm 2.13 \%)$ of AMT. In addition, MS revealed decent buoyancy $(78.60 \pm 3.3 \%)$ and mucoadhesion $(78.25 \pm 0.14 \%)$ ability along with good floating lag time ( $>20 \mathrm{~min}$ ). On the other hand, in vitro results advocated sustained release profile of AMT for up to $24 \mathrm{~h}$. As hypothesized, fluorescence (in vivo) study confirmed prolonged retention of MS in the stomach. In conclusion, MS with dual qualities (i.e., floating and mucoadhesive) can be used for attaining encouraging effect (in vitro) against $H$. pylori infection. 


\section{Acknowledgement}

One of the authors, Debashish Nayak, expresses his sincere thanks to University Grants Commission, New Delhi, India for awarding the Junior Research Fellowship during his PG programme.

\section{Declaration of Interest}

The authors report no declarations of interest.

\section{References}

1. Warren JR, Marshall B (1983) Unidentified curved bacilli on gastric epithelium in active chronic gastritis. The lancet 321: 1273-1275.

2. Jain SK, Jangdey MS (2009) Lectin conjugated gastroretentive multiparticulate delivery system of clarithromycin for the effective treatment of Helicobacter pylori. Mol Pharm 6: 295-304.

3. Jain SK, Gupta M, Sahoo AK, Pandey AN, Jain AK (2014) Lectin conjugated gastro-retentive microspheres of amoxicillin for effective treatment of Helicobacter pylori. Curr Sci 106(2): 267-276.

4. Jain SK, Sahoo AK, Gupta M, Pandey AN, Kumar A, et al. (2014) Delivery of repaglinide-cholestyramine complex loaded ethylcellulose microspheres to gastric mucosa for effective management of type-2 diabetes mellitus. Curr Sci 106(11): 1518-1528.

5. Jain SK, Haider T, Kumar A, Jain A (2016) Lectin-Conjugated Clarithromycin and Acetohydroxamic Acid-Loaded PLGA Nanoparticles: A Novel Approach for Effective Treatment of $\mathrm{H}$. pylori. AAPS PharmSciTech 17: 1131-1140.

6. Jain SK, Prajapati N, Rajpoot K, Kumar A (2016) A novel sustained release drug-resin complex-based microbeads of ciprofloxacin $\mathrm{HCl}$. Artif Cells Nanomed Biotechnol 44:1891-1900.

7. Jain SK, Patel K, Rajpoot K, Jain A (2019) Development of a Berberine Loaded Multifunctional Design for the Treatment of Helicobacter pylori Induced Gastric Ulcer. Drug Deliv Lett 9: 50-57.

8. Jain SK, Patel K, Rajpoot K, Jain A (2019) Development of a Berberine Loaded Multifunctional Design for the Treatment of Helicobacter pylori Induced Gastric Ulcer. Drug Deliv Lett 9: 50-57.

9. Irwin WJ, Belaid KA, Alpar HO (1987) Drug-delivery by ion-exchange: Part IIII: Interaction of ester pro-drugs of propranolol with cationic exchange resins. Drug Develop Ind Pharm 13: 2047-2066.

10. Sriwongjanya M, Bodmeier R (1997) Entrapment of drug-loaded ionexchange particles within polymeric microparticles. Int J Pharm 158 29-38.

11. Chaudhry NC, Saunders L (1956) Sustained release of drugs from ion exchange resins. J Pharm Pharmacol 8: 975-983.

12. Junyaprasert VB, Manwiwattanakul G (2008) Release profile comparison and stability of diltiazem-resin microcapsules in sustained release suspensions. Int J Pharm 352: 81-91.

13. Akbari BV, Patel BP, Dholakiya RB, Shiyani BG, Lodhiya DJ (2010) Development and evaluation of taste masked suspension of prokinetic agent by using ion exchange resin. Int J PharmTech Res 2: 240-245.

14. Kouchak M, Atyabi F (2004) Ion-exchange, an approach to prepare an oral floating drug delivery system for diclofenac. Iran J Pharm Res 3: 9397.

15. Ichikawa H, Fujioka K, Adeyeye MC, Fukumori Y (2001) Use of ionexchange resins to prepare $100 \mu \mathrm{m}$-sized microcapsules with prolonged drug-release by the Wurster process. Int J Pharm 216: 67-76.

16. Halder A, Sa B (2006) Sustained release of propranolol hydrochloride based on ion-exchange resin entrapped within polystyrene microcapsules. J Microencapsul 23: 899-911.

17. Jeong SH, Berhane NH, Haghighi K, Park K (2007) Drug release properties of polymer coated ion-exchange resin complexes: Experimental and theoretical evaluation. J Pharm Sci 96: 618-632.
18. Merekar AN, Godge RK, Parjane SK, Kuchekar BS, Kendre PN, et al. (2010) Formulation and in vitro-in vivo evaluation of Salbutamol Sulphate sustained release tablets. Der Pharmacia Lett 2: 546-552.

19. Steel JC, Cavanagh HM, Burton MA, Dingwall D, Kalle WH (2004) In-vitro evaluation of ion-exchange microspheres for the sustained release of liposomal-adenoviral conjugates. J Control Release 95: 601-611.

20. Jackson SJ, Bush D, Washington N, Perkins AC (2000) Effect of resin surface charge on gastric mucoadhesion and residence of cholestyramine. Int J Pharm 205: 173-181.

21. Burton S, Washington N, Steele RJ, Musson R, Feely L (1995) Intragastric distribution of ion-exchange resins: A drug delivery system for the topical treatment of the gastric mucosa. J Pharm Pharmacol 47: 901-906.

22. Thairs S, Ruck S, Jackson SJ, Steele RJC, Feely LC, et al. (1998) Effect of dose size, food and surface coating on the gastric residence and distribution of an ion exchange resin. Int J Pharm 176(1): 47-53.

23. Liu Z, Lu W, Qian L, Zhang X, Zeng P, et al. (2005) In vitro and in vivo studies on mucoadhesive microspheres of amoxicillin. J Control Release 102(1): 135-144.

24. Umamaheshwari RB, Jain S, Jain NK (2003) A new approach in gastroretentive drug delivery system using cholestyramine. Drug Deliv 10(3): 151-160.

25.Zhou Q Wang M, Li A, Shuang C, Zhang M, et al. (2013) Preparation of a novel anion exchange group modified hyper-crosslinked resin for the effective adsorption of both tetracycline and humic acid. Frontiers Environ Sci Eng 7: 412-419.

26. Paavonen J, Roberts PL, Stevens CE, Wolner Hanssen P, Brunham RC, et al. (1989) Randomized treatment of mucopurulent cervicitis with doxycycline or amoxicillin. Am J Obstet Gynecol 161: 128-135.

27. Jain SK, Kumar A, Kumar A, Pandey AN, Rajpoot K (2016) Development and in vitro characterization of a multiparticulate delivery system for acyclovir-resinate complex. Artif Cells Nanomed Biotechnol 44(5): 1266-1275.

28. Jeong SH, Park K (2008) Development of sustained release fastdisintegrating tablets using various polymer-coated ion-exchange resin complexes. Int J Pharm 353(1-2): 195-204.

29. Pongjanyakul T, Prakongpan S, Rungsardthong U, Chancham P, Priprem A (2005) Characteristics, and in vitro release of dextromethorphan resinates. Powder Technol 152: 100-106.

30. Patrey NK, Rajpoot K, Jain AK, Jain SK (2016) Diltiazem loaded floating microspheres of Ethylcellulose and Eudragit for gastric delivery: In vitro evaluation. AJBR 2: 71-77.

31. Kamila MM, Mondal N, Ghosh LK, Gupta BK (2009) Multiunit floating drug delivery system of rosiglitazone maleate: Development, characterization, statistical optimization of drug release and in vivo evaluation. AAPS Pharm Sci Tech 10(3): 887.

32. Jain SK, Awasthi AM, Jain NK, Agrawal GP (2005) Calcium silicate-based microspheres of repaglinide for gastroretentive floating drug delivery: preparation and in vitro characterization. J Control Release 107: 300309.

33. Boyd GE, Adamson AW, Myers LS (1947) The exchange adsorption of ions from aqueous solutions by organic zeolites; kinetics. J Am Chem Soc 69: 2836-2848.

34. Bhaskar R, Murthy RSR, Miglani BD, Viswanathan K (1986) Novel method to evaluate diffusion-controlled release of drug from resinate. Int J Pharm 28(1): 59-66.

35. Ritger PL, Peppas NA (1987) A simple equation for description of solute release II. Fickian and anomalous release from swellable devices. J Control Release 5: 37-42.

36. Cuna M, Alonso MJ, Torres D (2001) Preparation, and in vivo evaluation of mucoadhesive microparticles containing amoxycillin-resin complexes for drug delivery to the gastric mucosa. Eur J Pharm Biopharm 51: 199205. 
37. Pisal S, Zainnuddin R, Nalawade P, Mahadik K, Kadam S (2004) Drug release properties of polyethylene-glycol-treated ciprofloxacin-Indion 234 complexes. AAPS Pharm Sci Tech 5(4): 101-106.

38. Tao Y, Lu Y, Sun Y, Gu B, Lu W, et al. (2009) Development of mucoadhesive microspheres of acyclovir with enhanced bioavailability. Int J Pharm 378: $30-36$

\section{ISSN: 2574-1241}

DOI: $10.26717 /$ BJSTR.2020.29.004847

Sunil K Jain. Biomed J Sci \& Tech Res

(C) (P) This work is licensed under Creative

Submission Link: https://biomedres.us/submit-manuscript.php
39. Adeyeye MC, Mwangi E, Katpally S, Fujioka K, Ichikawa H, et al. (2005) Suspensions of prolonged-release diclofenac-Eudragit and ion-exchange resin microcapsules: II. Improved dissolution stability. J Microencapsul 22(4): 353-362.

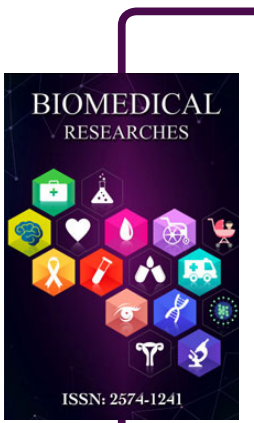

Assets of Publishing with us

- Global archiving of articles

- Immediate, unrestricted online access

- Rigorous Peer Review Process

- Authors Retain Copyrights

- Unique DOI for all articles

https://biomedres.us/ 